\title{
10 de diciembre: día internacional de los derechos humanos
}

\author{
December $10^{\text {th }}$ : International Human Rights Day \\ 10 de dezembro: dia internacional dos direitos humanos \\ Diana Cárdenas*
}

https://doi.org/10.35454/rncm.v4n4.356

\begin{abstract}
"En definitiva, ¿dónde empiezan los derechos humanos universales? En pequeños lugares, cerca de casa; en lugares tan próximos y tan pequeños que no aparecen en ningún mapa (...). Si esos derechos no significan nada en estos lugares, tampoco significan nada en ninguna otra parte. Sin una acción ciudadana coordinada para defenderlos en nuestro entorno, nuestra voluntad de progreso en el resto del mundo será en vano". Eleonor Roosevelt.

El 10 de diciembre de cada año se conmemora el día en que, en 1948, la Asamblea General de las Naciones Unidas adoptó la Declaración Universal de Derechos Humanos (DUDH). Se trata de un documento histórico que proclamó los derechos inalienables inherentes a todos los seres humanos, sin importar su raza, color, religión, sexo, opiniones políticas o de otra índole, origen nacional o social, lugar de nacimiento, ni ninguna otra condición. Allí se proclaman sus principios como "un ideal común para todos los pueblos y naciones". No se trata de un documento que promueve ideales utópicos inalcanzables; por el contrario, gracias a este documento y el compromiso de los Estados con sus principios, la vida de millones de personas ha mejorado y se han sentado las bases de un mundo más justo. Sin embargo, aún existen muchos espacios donde no se respetan los derechos y los valores que en este documento se promueven. Es por esto que este día brinda a todos la oportunidad de renovar el espíritu de lucha de la humanidad por los derechos y la dignidad. También es la oportunidad de movilizarse contra los desafíos que se manifiestan en forma de pobreza, desigualdad, violencia, exclusión y discriminación.
\end{abstract}

Reconociendo que los derechos humanos deben ser el fundamento de todos los progresos, y que la ciencia

*Correspondencia: Diana Cárdenas.

dianacardenasbraz@gmail.com es un bien común, la Revista busca el desarrollo de la ciencia de la nutrición clínica y la promoción del derecho humano al cuidado nutricional. La ciencia es un derecho cultural que debe servir para el beneficio de la sociedad. Este derecho se debe entender más allá del simple derecho al acceso a lo material; por ejemplo, acceso a un nuevo fármaco, ya que implica principalmente la defensa del acceso al conocimiento y el derecho que tienen todos de participar en la ciencia. Sin embargo, en los últimos años ha habido un creciente desprecio por el conocimiento, con la difusión de noticias falsas y las prácticas basadas en creencias y mitos. En este contexto, la misión de la Revista es promover el respeto por el conocimiento publicando, en acceso abierto, artículos que cumplan con altos estándares científicos.

El conocimiento de la nutrición clínica y sus aplicaciones deben estar alineados con los 13 principios de la Declaración de Cartagena y, en particular, de la DUDH. Los invitamos a que renueven su compromiso con los derechos y la dignidad de las personas enfermas, y sigan comprometidos con los valores universales que la DUDH promueve en todas las sociedades y todas las circunstancias.

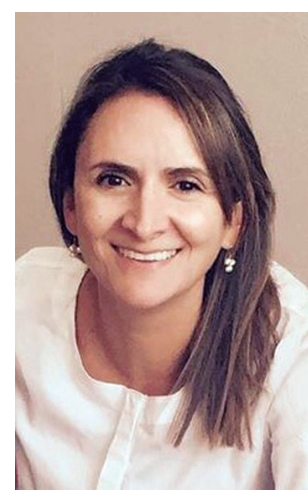

Diana Cárdenas, MD, PhD Editora de la Revista de Nutrición Clínica y Metabolismo. Profesora e investigadora del Instituto de Nutrición, Genética y Metabolismo, Facultad de Medicina, Universidad El Bosque. Bogotá, Colombia. 